\title{
ENERGY EFFICIENCY AND PERFORMANCE OF SERVOPNEUMATIC DRIVES FOR SPEED GOVERNORS BASED ON OPERATING POINTS
}

\author{
Vinícius Vigolo ${ }^{1}$, Gregori Conterato ${ }^{1}$, Talles Spada ${ }^{1}$, Leonardo Augusto Weiss ${ }^{2}$, Victor \\ Juliano De Negri ${ }^{1 *}$ \\ ${ }^{1}$ Mechanical Engineering Department, Federal University of Santa Catarina, Trindade, 88040-900, Florianópolis, \\ Brazil \\ ${ }^{2}$ Reivax S/A Automation and Control, João Paulo, 88030-904, Florianópolis, Brazil \\ * Corresponding author Tel.: +55 483721 9396; E-mail address: victor.de.negri@ufsc.br
}

\begin{abstract}
In this paper, the energy efficiency and dynamic performance of servopneumatic drivers are studied aiming at the correct sizing of the system components. The study is carried out through a non-linear dynamic model of a servopneumatic system. The simulation data are used along with the operating point method in order to understand the effect of loading conditions in the system performance, which is then used as a tool for component sizing. The results show the effects that the piston area has on the energy efficiency and dynamic behavior of the system. Moreover, the dependency of the servovalve size on the piston area is elucidated. A procedure to design an effective combination of piston area and sonic conductance of the servovalve is presented. A practical case where a servopneumatic system is being designed for the speed governor of a hydraulic turbine is described, evidencing the suitability of the proposed method for servopneumatic systems.
\end{abstract}

Keywords: Servopneumatic systems, sizing method, operating point, turbine speed governors

\section{INTRODUCTION}

Pneumatic systems are widely used in the automation industries due to its low acquisition and maintenance costs, high reliability and high power/weight ratio, beyond that they provide speedy actuations. Pneumatic systems are being used for point-to-point automation purposes since the 60's [1] and in the 80's the first commercial servopneumatic system has been made available [2]. Since then, the application of servopneumatic systems has increased widely, being applied in the fields of automation, robots and manufacturing. According to [3], pneumatic servosystems are capable to replace electromechanical and hydraulic actuators, which are less efficient and costly [4] and [5].

In the past few decades, many control strategies have been developed for pneumatic servosystems, including linear and nonlinear controls, fuzzy based techniques and state observers with compensators strategies [3]. In the same way the mathematical modelling also had many improvements, for which models for nonlinearities such as the piston friction, end stroke cushioning and valve mass flow rate have been developed. These models are combined with equations based on the physical principles that govern the system, resulting in a global model capable to predict the behavior of the state variables of the drive with high accuracy [2].

However, in the sense of pneumatic system sizing, there is still the need of consistent method for the selection of the system components. An optimal system design is proposed by [6], even so the method is based on an optimization algorithm, which limits the applicability of the method for software implementing tools. On its review on recent research trends in servo pneumatic systems, [3] describes the systems parameters that have a significant impact in the system dynamic. Still, no guidelines are given in order to select the main components.

In this context, this paper studies the characteristic behavior of a servopneumatic system in order to propose guidelines to size the systems parameters. The inflection point of the velocity profile and the operating point of system are used as key points in the design process of the servovalve and the cylinder diameter. 


\section{MATHEMATICAL MODEL}

A conventional servopneumatic system is presented in Figure 1. It is composed by a cylinder, a servovalve (SV), a position transducer, a set of hoses and a controller, which receives the position error and sends the control signal to the SV.

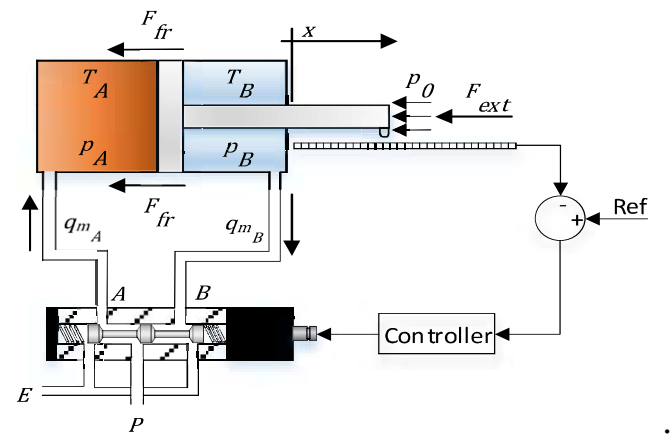

Figure 1: Conventional servopneumatic system

In this study, the components were modelled according to the physical laws that govern the system, including the mass flow rate through the valve, the pressure and temperature inside the cylinder chambers, the motion and friction of the piston. The heat exchange in the actuator is modelled by the Newton's law of cooling and the friction is described by the LuGre Model [7]. These equations result in a non-linear model which is described in [8] and implemented in MATLAB/Simulink ${ }^{\circledR}$ for simulation purposes. The pressure and thermal losses in the hoses were neglected since the PDV is usually connected close to the actuator and their effects on the system dynamics might be included in the dead volume of the cylinder chambers. An experimental validation is performed in order the evaluate the effectiveness of the model and the results are presented in [8].

\section{ANALYSIS OF THE SYSTEM DYNAMICS}

A servo pneumatic actuator is, in the point of view of control, a system working in closed loop, where the output is the piston position and the input is a reference position of the actuator stroke. As in many control systems, the general response of a servo pneumatic system might be approximate by a second order system, that is

$\frac{y(s)}{y_{R e f}(s)}=\frac{\omega_{n}^{2}}{s^{2}+2 \zeta \omega_{n} s+\omega_{n}^{2}}$.

This approach is convenient since the design requirements are easily converted into a second order system parameter, such as natural frequency and damping ratio. A similar approach is used in [9] and [10], where a design method for hydraulic positioning system is proposed.

\subsection{Inflection point of a step response}

The design requirements of a positioning system usually are composed by the maximum displacement, settling time, maximum forces and overshoot. Therefore, the design requirements can be converted into natural frequency and damping ratio by the settling time

$t_{s}=\frac{6}{\omega_{n}} \quad$ for $\quad \zeta=1$

or

$t_{s}=\frac{5.7}{\omega_{n}} \quad$ for $\quad \zeta=0.7$

In a second order system, the maximum velocity occurs at the inflection point of the velocity profile. At this point, the acceleration is null and the velocity is given by.

$v_{\max }=0.4668 x_{\max } \omega_{n}$ for $\zeta=0.7$

or

$v_{\max }=0.3678 x_{\max } \omega_{n}$ for $\zeta=1$

where $x_{\max }$ stands for the expected maximum step response [9].

Figure 2 presents an example of a step response of a servo pneumatic system along with the response of second order system with $\omega_{n}=$ $1.772 \mathrm{rad} / \mathrm{s}$ and $\zeta=1$.

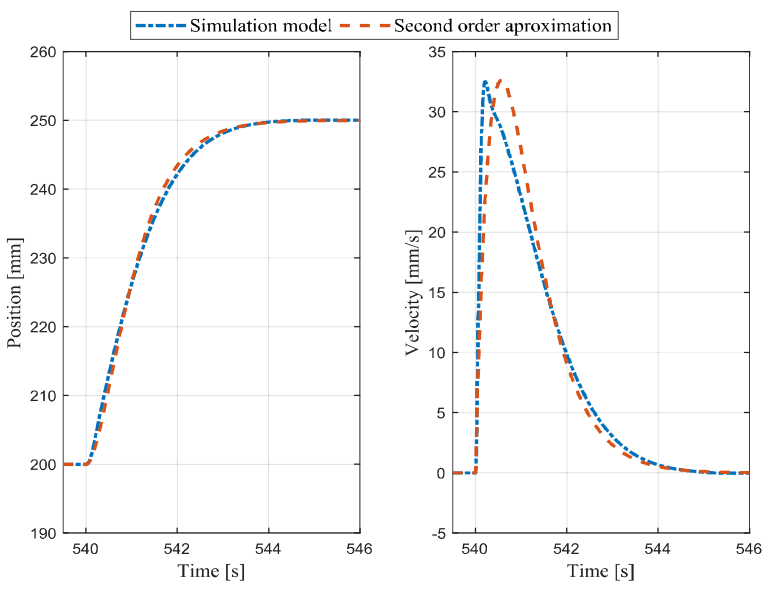

Figure 2: Comparison of a simulation model with a second order system

It can be seen that the characteristic second order model is capable to represent accurately the dynamic of the servopneumatic system, demonstrating the applicability to estimate the 
maximum velocity through the design requirements.

\subsection{System simulation analysis}

The effects of the chamber pressures during the displacement of the piston have an important impact on the system dynamics. Consequently, it is important to understand the characteristic behavior of the system in order to size it accordingly. As an example, a sequence of 10 step inputs, each one of $10 \%$ of the actuator stroke, was analyzed.

An important aspect of the study is that the closed loop control has a direct impact in the results. Therefore, the closed loop control is made with a simple proportional controller. The gain is calculated in such a way that the maximum error results in $100 \%$ of the valve opening and the sonic conductance was adjusted to have a critical damping behavior. The parameters of the system are presented in Table 1.

Table 1: Parameters of the simulation

\begin{tabular}{ll}
\hline Parameter & Value \\
\hline Piston diameter $D_{p}$ & $0.032 \mathrm{~m}$ \\
Rod diameter $D_{r}$ & $0.012 \mathrm{~m}$ \\
Area ratio $r_{A}$ & 0.8594 \\
Cylinder stroke L & $0.5 \mathrm{~m}$ \\
System mass M & $8.6 \mathrm{~kg}$ \\
Load force $F_{L}$ & $470 \mathrm{~N}$ \\
Viscous friction coefficient B & $200 \mathrm{~N} . \mathrm{s} / \mathrm{m}$ \\
Supply pressure $p_{s}$ & $8 \mathrm{bar}$ \\
Sonic conductance $C$ & $6 \times 10^{-10} \mathrm{~m}^{5} / \mathrm{N} . \mathrm{s}$ \\
Critical pressure ratio $b$ & 0.3 \\
\hline
\end{tabular}

Results from simulation of the pneumatic positioning system are presented in Figures 3 to 5.

It can be seen that the maximum velocity is not constant throughout the piston stroke. This fact is mainly related to the amount of air inside the counter pressure chamber, which is maximum in the beginning of the movement and reduces at each step. However, either the pressures and the maximum velocity tends to be constant as the piston reaches its end stroke. Further analysis related to these simulations are presented in Chapter 4.

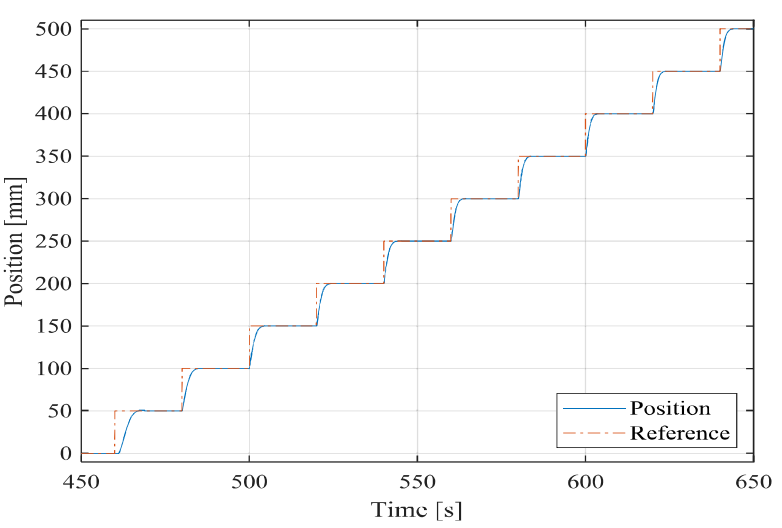

Figure 3: Reference and piston positions

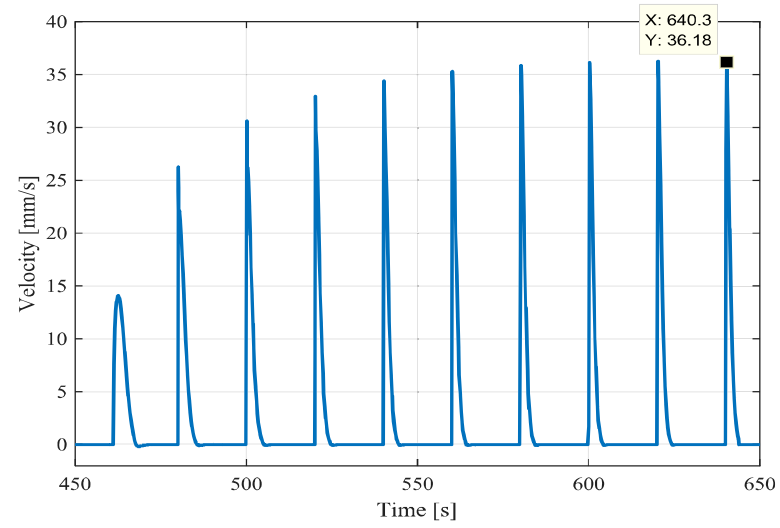

Figure 4: Piston velocity

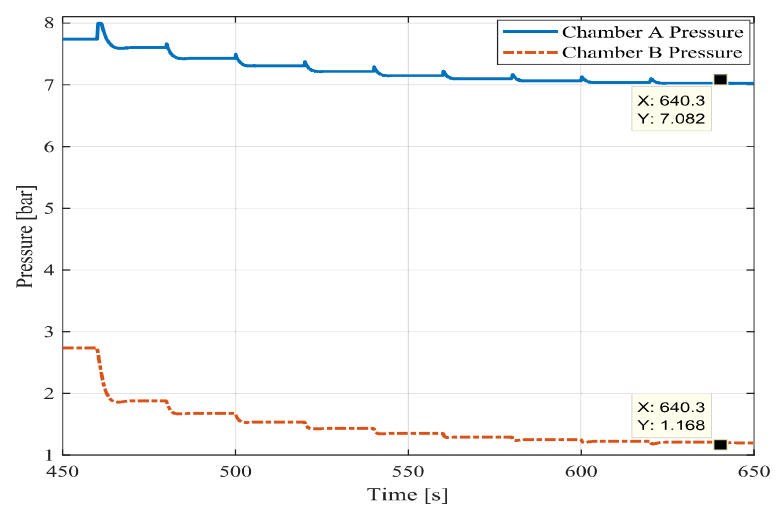

Figure 5: Chamber pressures

\section{STEADY STATE ANALYSIS}

The inflection point of the velocity has important characteristics that might be used for sizing purposes. For this reason, the pressure of both chambers was recorded at the inflection point in order to obtain the pressure ratios at this condition.

The operating point method was introduced by [11] and [12] and it describes the pressures of the system as a function of pressure ratios, for instance, in the extending movement $p_{A} / p_{S}$ is a function of $p_{0} / p_{B}$. 
As shown in Figure 6, the pressure ratios $\left(p_{A} / p_{S}\right.$ and $\left.p_{0} / p_{B}\right)$ at the maximum velocity points result in ten different operating points (red circles). They are analyzed along with the operating point chart, which is composed of a constant pressure curve ( $O p$ curve) and a constant velocity curve ( $L d g$ curve). The intersection of both curves occurs when both pressure and velocity are constant. The curves are described by

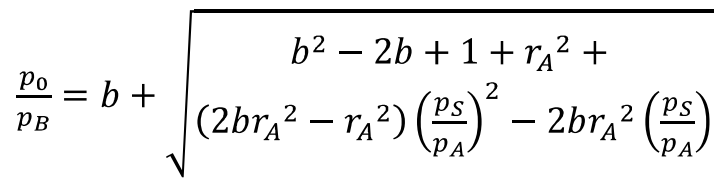

and

$$
\frac{p_{A}}{p_{S}}=\frac{F_{T}}{p_{S} A_{A}}+\left(\frac{p_{B}}{p_{0}}\right)\left(\frac{p_{0}}{p_{S}}\right) r_{A}+\frac{p_{0}}{p_{S}}\left(1-r_{A}\right) .
$$

where Equation (6) corresponds to the $O p$ curve and Equation (7) to the $L d g$ curve. The cylinder area ratio is defined as $r_{A}=A_{B} / A_{A}$. The equation derivations for this forward movement as well as for returning movement are presented in [12].

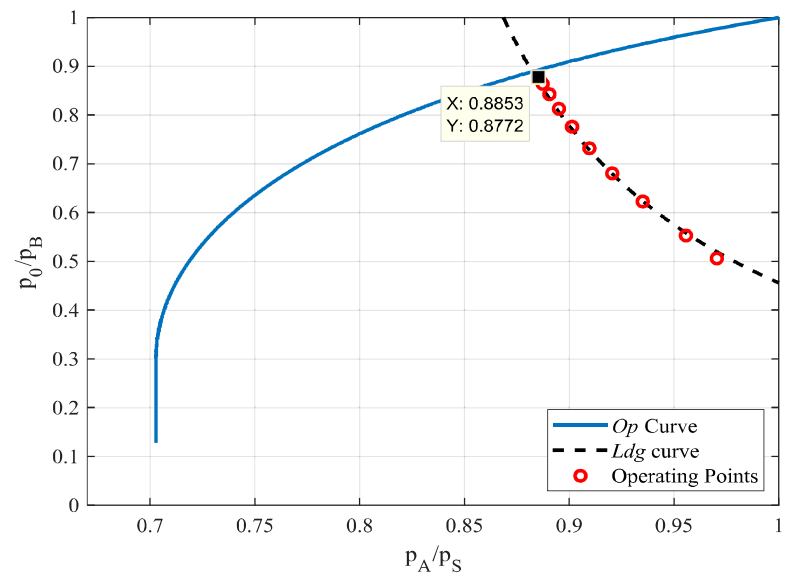

Figure 6: Operating point chart

The highlighted point corresponds to the last maximum velocity peak, whereas the first circle from right to left corresponds to the first maximum velocity peak. It can be seen that during the displacement of the piston along its stroke, the pressure ratios of the maximum velocity points are located exactly on the $L d g$ curve, which is due the nullity of acceleration at this point. It is also important to notice that the intersection between both curves occurs at the higher value of the maximum velocities and all the remaining points are below to the $O p$ curve.

The $O p$ curve is dependent of critical pressure ratio $(b)$ and the area ratio $\left(r_{A}\right)$, which are parameters that have a small influence on the dynamic behavior of the system. Usually, even when these parameters are not known, assuming typical values is enough to obtain the $O p$ curve. However, the $L d g$ curve depends on the load force and the piston area, that means, from the different loading ratios $\left(F_{T} / p_{S} A_{A}\right)$. Therefore, the obtaining of the $L d g$ curve depends on the determination of the chamber A piston area and the supply pressure, which will be discussed in Chapter 5.

\section{PISTON DIAMETER DETERMINATION}

For the same pneumatic actuation system, the variation of the piston diameter has a significant influence on the dynamic of the system. The main aspects are related to velocity, displacement time and energy efficiency [8].

In order to understand the effects of the piston diameter in the dynamic of a pneumatic servosystem, a sensitivity analysis is performed with 6 different diameters simulated under the same loading conditions, including the viscous friction coefficient and the area ratio. Table 2 presents the parameters of the different cylinder used on the sensitivity analysis. The loading ratio $\left(L_{r}\right)$ is given by:

$L_{r}=\frac{F_{L}+p_{S} A_{A} \mu}{p_{S} A_{A}}=\frac{F_{T}}{p_{S} A_{A}}$

where $F_{L}$ stands for the load force $(470 \mathrm{~N})$ and the parcel $p_{S} A_{A} \mu$ represents the friction force, where $\mu$ is the coefficient that correlates the friction force with the maximum force in the chamber A of the actuator. Due to the low velocities, $\mu$ was assumed to be $1 \%$.

Table 2: Cylinder data for the sensitivity analysis

\begin{tabular}{ccc}
\hline $\begin{array}{c}\text { Piston diameter } \\
{[\mathrm{mm}]}\end{array}$ & $\begin{array}{c}\text { Rod diameter } \\
{[\mathrm{mm}]}\end{array}$ & $\begin{array}{c}\text { Loading ratio } \\
{[1]}\end{array}$ \\
\hline 30 & 11.25 & 0.8411 \\
32 & 12 & 0.7405 \\
34 & 12.75 & 0.6571 \\
36 & 13.5 & 0.5872 \\
38 & 14.25 & 0.5280 \\
40 & 15 & 0.4775 \\
\hline
\end{tabular}

Figure 7 presents the operating point chart with the results of the 6 simulations from the sensitivity analysis.

It can be seen that each loading ratio resulted in a different $L d g$ curve and the pressure ratios at the maximum velocity points lie on the $L d g$ 
curve. Moreover, for lower loading ratios, the pressure ratios no longer reach the $O p$ curve, a similar behavior occurs for point to point applications, as described in [8].

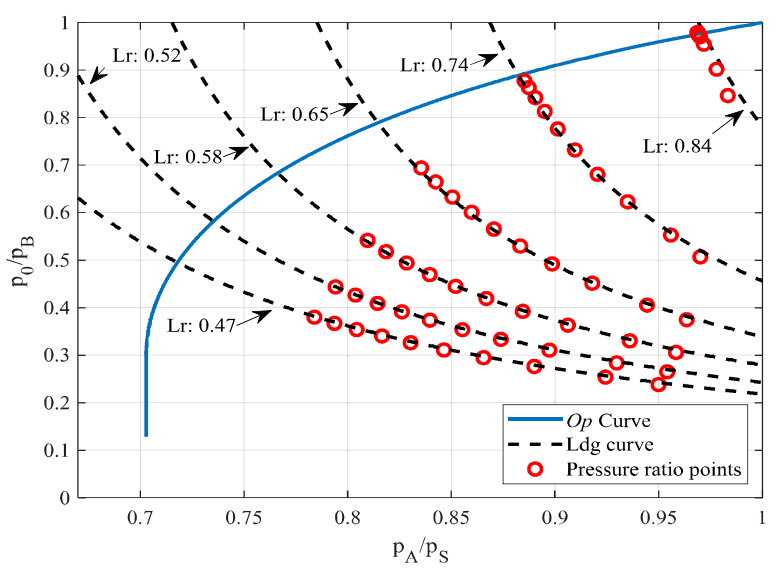

Figure 7: Operating point chart for different loading conditions

The main aspect related to this analysis is the choice of the best loading ratio. To support this decision, Figure 8 presents the maximum velocity of the last step (Figures 3 ) and the energy efficiency along with the loading ratio. The energy efficiency is the ratio of the delivered pneumatic energy with the supplied exergy, the calculus procedure is presented in [8].

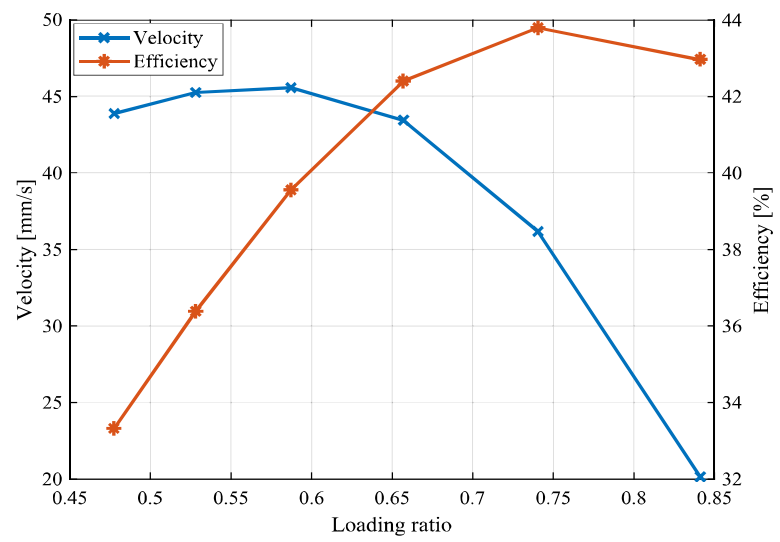

Figure 8: Maximum velocity and energy efficiency for different loading ratios

Figure 8 shows that as the piston diameter increases, the maximum velocity and the energy efficiency increases up to a limit. At a certain point, both start to decrease, pointing out the importance of a correct sizing of the actuator. In this case, the best configuration occurs with $L r \cong$ 0.63 , which is close to the maximum velocity condition.

In order to estimate this optimal condition for a general system, Equation 9 might be used, resulting on an expression of Velocity/Sonic Conductance $(C)$ ratio as a function of the pressure ratio under the hypothesis of constant speed and pressure [8], as exemplified in Figure 9.

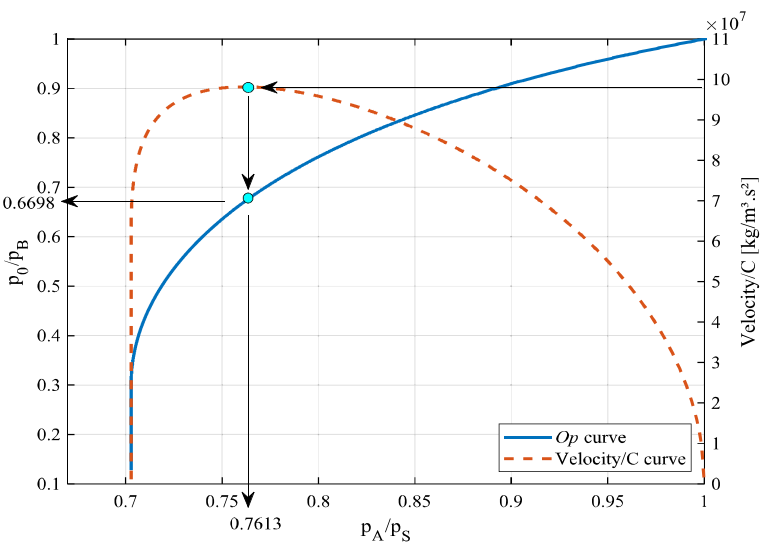

Figure 9: Determination of the maximum velocity point

By the Velocity/C curve, the $p_{A} / p_{S}$ value corresponding to the maximum steady state velocity is obtained. This pressure ratio is then applied in Equation 6 in order to obtain the corresponding $p_{0} / p_{B}$ ratio. Both pressure ratios are substituted in Equation 7, yielding a loading ratio corresponding to an optimum condition $\left(L_{\text {ropt }}\right)$, which is, in this case, 0.5789 . As can be seen, this method results in a loading ratio close to the maximum velocity condition shown in Figure 8, which has a loading ratio of 0.5847 .

Once the optimum loading ratio is defined, the piston area or the supply pressure can be calculated by

$A_{A}=\frac{F_{L}}{p_{S}\left(L_{r o p t}-\mu\right)}$. 


\section{SERVOVALVE DESIGN}

The sizing of the servovalve is an important step to guarantee the system dynamics since it controls the airflow rate to the cylinder [3]. The sizing of the proportional valve (or servovalve) might not be done isolate, since the piston diameter also affects the dynamic behavior of the system [8]. For this reason, the continuity equation for the cylinder chambers must be analyzed along with the mass flow rate equation through the valve.

Applying the continuity equation to the chamber A of the actuator (Figure 1), under the hypothesis of isothermal process, results in:

$\frac{d p_{A}}{d t}=\frac{1}{V_{A}}\left(q_{m_{P-A}} T_{A} R-p_{A} A_{A} \frac{d x}{d t}\right)$.

The mass flow rate from the constant pressure source to the chamber A is defined by the ISO 6358-1 (2013) standard [13]. Assuming a subsonic flow and a supply temperature equal to the ambient temperature:

$q_{m_{P-A}}=p_{S} C \frac{U}{U_{n}} \rho_{0} \sqrt{1-\left(\frac{\frac{p_{A}}{p_{S}}-b}{1-b}\right)^{2}}$.

Combining Equations 11 and 12, and assuming the chamber A temperature to be equal to the ambient temperature, the sonic conductance becomes

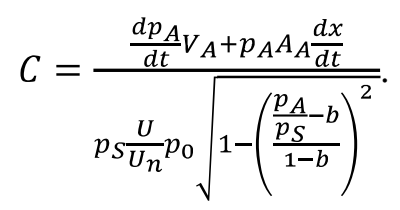

Equation 13 presents the parameters that should be accounted during the sizing process. Considering that the maximum velocity point is a critical condition for the servovalve, Equation 13 might be used with the parameter values of the inflection point of the step response.

During the design process, the maximum velocity is estimated using Equation 4 or 5 . The piston area shall be determined using the Equation 10. The ratio $U / U_{n}$ might be considered as 1 , since the control signal at the maximum velocity usually is close to the maximum opening of the servovalve. The critical pressure ratio $(b)$ has its maximum theoretical value equal to 0.528 , however, commercial valves always have a lower value, usually around 0.3 .

Through simulation analysis, the parcel relative to the derivative of pressure of Equation
13 has been found to be negative at the point of maximum velocity. Besides that, the product of $V_{A} d p_{A} / d t$ represents around $15 \%$ of $p_{A} A_{A} d x / d t$ parcel. Consequently, neglecting the derivative of pressure parcel it results on a higher sonic conductance, which is favorable for the sizing process.

The remaining parameter to be determined in order to calculate the sonic conductance in Equation 13 is the $p_{A} / p_{S}$ ratio. Analyzing the Figures 6 and 7, it can be seen that the pressure ratios are not constant throughout the piston stroke and they lie over the $L d g$ curve. Since the $p_{A} / p_{S}$ for the maximum velocity can be calculated by Equation 9, it is suggested to choose an average value between 1 and the pressure ratio at maximum velocity, as it represents an average working condition along the cylinder stroke. The average pressure ratio is given by

$$
\left(p_{A} / p_{S}\right)_{A v}=\frac{1+\left(p_{A} / p_{S}\right)_{v_{\max }}}{2} \text {. }
$$

Under the assumptions presented above, the servovalve can be sized according to

$$
C=\frac{\left(p_{A} / p_{S}\right)_{A v} \cdot A_{A} \cdot v_{\max }}{p_{0} \sqrt{1-\left(\frac{\left(p_{A} / p_{S}\right)_{A v}-b}{1-b}\right)^{2}}} .
$$

\section{CASE STUDY}

In this chapter, the method presented above is applied for sizing the actuation system of a speed governor of a Francis hydraulic turbine, which is part of a research and development project that aims the replacement of hydraulic servomotors in small hydropower plants. The applicability of pneumatic servosystem for hydraulic speed governor was previously studied by [14] and [15].

\subsection{System description}

The speed governor of a hydraulic turbine is the system used to control the rotational velocity of the turbine, which should be held constant in order to maintain a constant frequency of the generated electric energy. The control is made by positioning of the guide vanes, increasing or decreasing the amount of water flowing through the turbine.

In this study, a real hydropower plant with net height of 18.5 meters and a Francis turbine with $438 \mathrm{~kW}$ of generation capacity is evaluated. The 
main requirements for the actuation system design are the speed governor time constant, the minimum opening time, the load force and the total stroke. Other requirements such as minimum closing time and emergency closing are related to an auxiliary actuation system and will not be discussed in this paper. Additional information about this system is presented in [5].

\subsection{Design requirements}

According to the standard IEC 61362 (2012) [16] the time constant $\left(\tau_{y}\right)$ of the speed governor should range between 0.10 to 0.15 seconds. Assuming a criterion of $1 \%$ of error, the settling time is 0.5 to 1.25 seconds $\left(5 \tau_{y}\right)$.

The load force caused by the water flow through the turbine is not constant. [17] presents a load profile where the maximum load occurs around $80-90 \%$ of the actuator stroke and the force is zero around $15 \%$ of the stroke.

The load profile proposed by [17] has an hysteresis between the opening and closing movement, which is due the water force in the blades. Due to the uncertainty on determining the transition between the opening and closing forces, [5] proposed an adjusted load profile which includes the maximum load force and the null force, as presented in Figure 10. This curve will be used for sizing and simulation purposes.

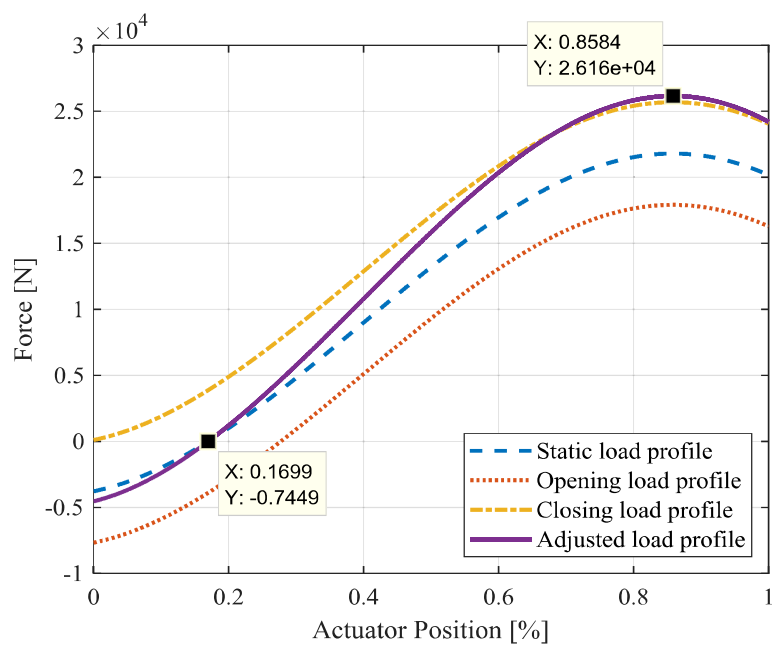

Figure 10: Load profiles in a Francis hydraulic turbine

The mounting of the guide vanes requires a total stroke of $131 \mathrm{~mm}$ for the actuation system. A step of $10 \%$ of the total stroke can be considered for the dynamic sizing of the actuation system.

\subsection{System sizing}

The first step to size the actuation system is the definition of the best piston area considering the system loading. In this case, the load is not constant throughout the piston stroke, however, in order to guarantee the dynamic performance required by the IEC 61362 Standard, the system must be sized for the worst-case scenario, which is the maximum load force.

The available pneumatic compressor is

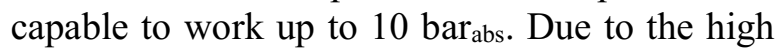
load involved, two actuators working in opposing conditions are used. It is equivalent of a single actuator with the resulting area equal to the sum of area $A_{A}$ and area $A_{B}$ of the actuators and the area ratio $\left(r_{A}\right)$ equal to 1 . The friction coefficient is estimated to be $1 \%$ of the maximum force in chamber $\mathrm{A}$ and the maximum load according to Figure 10 is $26.16 \mathrm{kN}$. The critical pressure ratio of the servovalve is estimated in 0.3. Based on that, Equation 9 is used to determine the velocity/C as a function of the $p_{A} / p_{S}$.

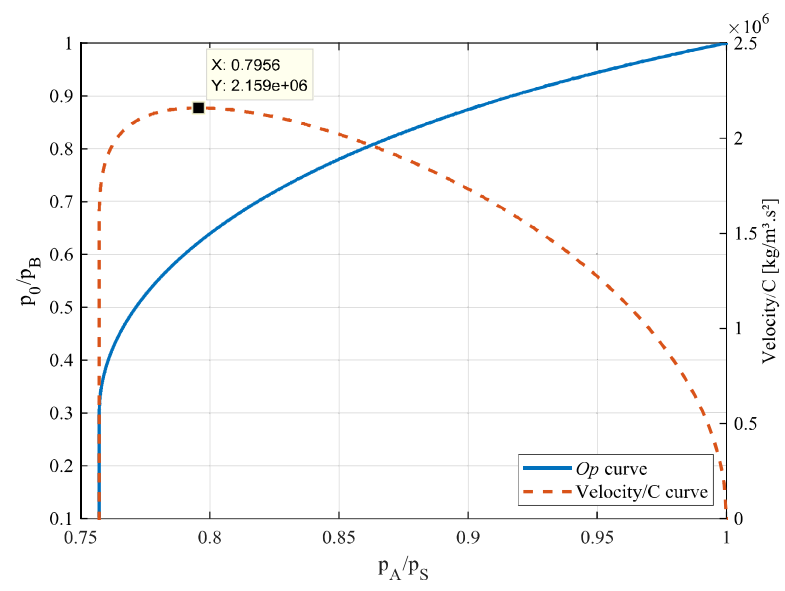

Figure 11: Point of maximum velocity

The pressure ratio $p_{A} / p_{S}$ at maximum velocity is 0.7956. The corresponding $p_{0} / p_{B}$ ratio is obtained by the Equation 6, which yields 0.6223 . The resulting loading ratio $\left(F_{T} / p_{S} A_{A}\right)$ is 0.6309 , which is given by Equation 7 .

Using Equation 10, the resulting piston area $\left(A_{A}\right)$ is $0.0421 \mathrm{~m}^{2}$, which is equivalent to a cylinder with $231 \mathrm{~mm}$ of piston diameter.

The closest commercial area is the combination of two cylinders with $160 \mathrm{~mm}$ of piston diameter and $40 \mathrm{~mm}$ of rod diameter. The total area is $0.038956 \mathrm{~m}^{2}$, resulting in a loading ratio of 0.6815 , which is higher than the ratio of the maximum velocity (0.6309). However, as it can be seen in Figure 8, loading ratios slightly 
higher than the maximum velocity results in higher energy efficiency. An acceptable loading ratio must be chosen carefully in order to avoid an undersized system. Figure 12 presents the $L d g$ curve of both loading ratios where it can be seen that the increasing of $L_{r}$ has a small impact at the velocity curve, which decreased just about $2 \%$.

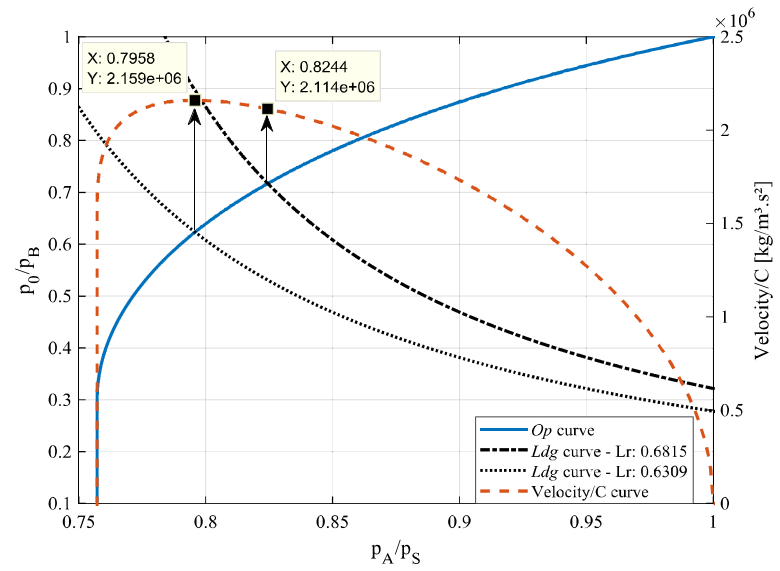

Figure 12: Velocity variation of both loading ratio

The natural frequency of the closed loop positioning system is given by Equation 3, where the settling time is set in 1.25 seconds $\left(5 \tau_{y}\right)$, in accordance with the IEC 61362 Standard. A small overshoot is acceptable, thus a damping ratio of 0.7 is assumed. Hence, the requested natural frequency is $4.56 \mathrm{rad} / \mathrm{s}$.

The velocity is obtained by Equation 4, where the expected maximum displacement is $10 \%$ of the total stroke, which yields $0.0219 \mathrm{~m} / \mathrm{s}$.

This velocity is used in Equation 15 to be calculating the sonic conductance of the servovalve. The $p_{A} / p_{S}$ of the dashed $L d g$ curve (Figure 12) may be adjusted according to the Equation 14 resulting on 0.8978 . Therefore, the result is $C=14.3629 \times 10^{-9} \mathrm{~m}^{5} / \mathrm{N}$.s. A commercial model with sonic conductance of $16.5 \times 10^{-9} \mathrm{~m}^{5} / \mathrm{N} . \mathrm{s}$ is chosen for this application. If the same procedure is applied to the dashdotted line, the resulting sonic conductance is $C=15.6579 \times 10^{-9} \mathrm{~m}^{5} / \mathrm{N}$.s.

Simulations were carried out with the designed values of the piston area and the sonic conductance of the servovalve. Figure 13 presents the results from two different simulations. One is with the exact parameters obtained from the design process and the other is with the commercially available components.

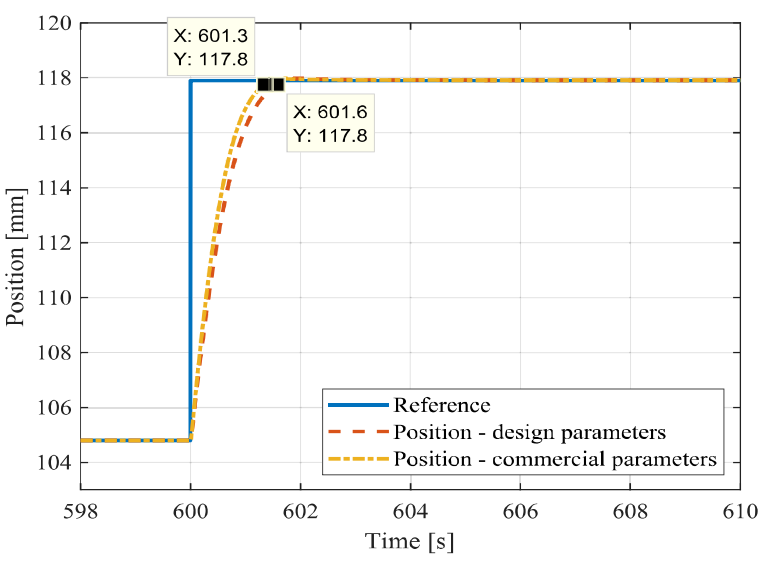

Figure 13: Simulation results of the designed systems.

The simulations are carried out at the most critical point, which is at $85 \%$ of the total stroke (maximum load). The proportional controller gain is set to 382 , which results in the total opening of the servovalve at the maximum velocity. According to the design process, the system should have a settling time of 1.25 seconds with overshoot. As can be seen, the settling time in both simulations is quite close from the design requirement and no significant overshoot is present in the step response.

It is important to highlight that the control plays an important role in the closed loop results. For this reason, the control gains should be tuned in a more effectively way, and/or an improved controller such as an adaptive PID controller should be used. As an example, the Figure 14 presents the system using commercial parameter with an increased gain of the proportional controller. The applied control signal to the servovalve is presented in Figure 15.

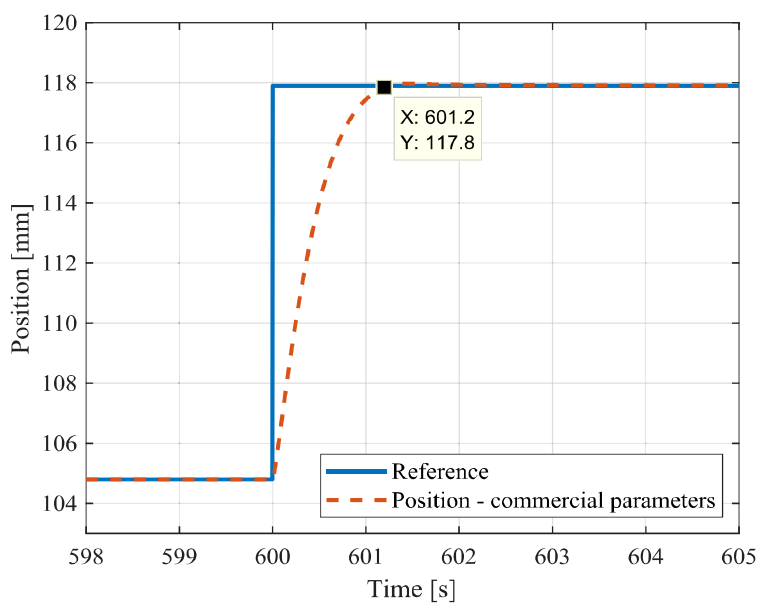

Figure 14: Simulation result with higher proportional gain 


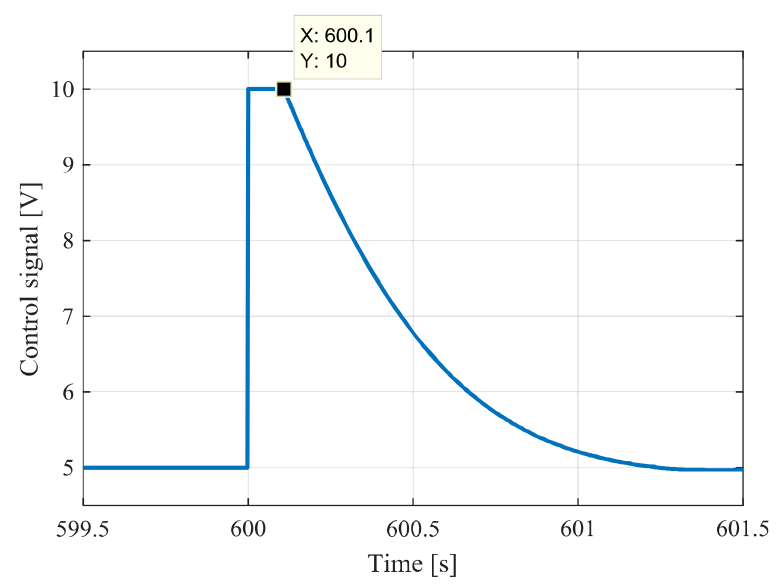

Figure 15: Servovalve control signal

As can be seen in Figure 15, with an adjusted controller the design requirements are achieved and the control signal sent to the servovalve shows that its imput voltage is saturated during less than $10 \%$ of the displacement, evidencing that the sonic conductance of the servovalve is adequate for the positioning task.

\section{CONCLUSION}

In this paper, the characteristic behavior of servopneumatic systems was studied aiming the correct sizing of the system components. The analysis was carried out by a non-linear dynamic simulation model implemented in MATLAB/Simulink ${ }^{\circledR}$ and the results from the inflection point of the position curve were studied with the operating point chart, which describes the system pressures under the hypothesis of constant speed and pressure.

The study showed that the piston size and the supply pressure affect the dynamic behavior and the energy efficiency of the system. An approach based on the operating point method and the position inflection point was proposed in order to design the system achieving the best dynamic and energetic performance as possible.

A case study was presented where the actuation system of a hydropower plant is being designed. The design requirements were converted into natural frequency, damping ratio and load force. An optimal loading ratio was determined for the piston diameter sizing and the combination of piston area with dynamic requirements were used to size the pneumatic servovalve.

The results presented in this paper evidence that the system sizing method is able to satisfactorily calculate the system parameters in order to attend the design requirements.

The main advantage of the proposed method is the possibility to design an efficient servopneumatic system, either in terms of energy efficiency and dynamic performance, through an analytical process which is based in the fundamental equations of the system. Since it does not require optimization algorithms, the method can be carried out with without the need of software or with simple spreadsheets.

It is important to highlight that the method presented is paper is not concluded yet, since many aspects of the design process are still object of study, such as the non-linear friction forces and different loading conditions. As a final result, a new methodology for pneumatic system sizing is expected.

\section{NOMENCLATURE}

\begin{tabular}{|c|c|}
\hline$\zeta$ & Damping ratio [1] \\
\hline$\mu$ & Friction coefficient $[1]$ \\
\hline$\rho_{0}$ & Density at ambient conditions $\left[\mathrm{kg} / \mathrm{m}^{3}\right]$ \\
\hline$\tau_{\mathrm{y}}$ & Time constant of speed governor [s] \\
\hline$\omega_{n}$ & Natural frequency $[\mathrm{rad} / \mathrm{s}]$ \\
\hline$A_{A}, A_{B}, A_{r}$ & Chamber A, B and rod area $\left[\mathrm{m}^{2}\right]$ \\
\hline$B$ & Viscous friction coefficient $[\mathrm{N} . \mathrm{s} / \mathrm{m}]$ \\
\hline$b$ & Critical pressure ratio [1] \\
\hline C & Sonic conductance $\left[\mathrm{m}^{5} / \mathrm{N} . \mathrm{s}\right]$ \\
\hline$D_{p}$ & Piston diameter $[\mathrm{m}]$ \\
\hline$D_{r}$ & Rod diameter $[\mathrm{m}]$ \\
\hline$F_{L}$ & Load force $[\mathrm{N}]$ \\
\hline$F_{\max }$ & Maximum force $[\mathrm{N}]$ \\
\hline$F_{T}$ & Total force $[\mathrm{N}]$ \\
\hline$L$ & Actuator stroke $[\mathrm{m}]$ \\
\hline$L_{r}$ & Loading ratio $[1]$ \\
\hline$M$ & Load mass $[\mathrm{kg}]$ \\
\hline$p_{A}$ & Chamber A pressure $\left[\mathrm{N} / \mathrm{m}^{2}\right]$ \\
\hline$p_{S, 0}$ & Supply and ambient pressure $\left[\mathrm{N} / \mathrm{m}^{2}\right]$ \\
\hline$q_{m}$ & Mass flow rate $[\mathrm{kg} / \mathrm{s}]$ \\
\hline$R$ & Ideal gas constant $[\mathrm{J} / \mathrm{kg} . \mathrm{K}]$ \\
\hline$r_{A}$ & Cylinder area ratio [1] \\
\hline$T$ & Temperature $[\mathrm{K}]$ \\
\hline$t$ & Time $[\mathrm{s}]$ \\
\hline$t_{s}$ & Settling time $[\mathrm{s}]$ \\
\hline U & Control signal $[\mathrm{V}]$ \\
\hline$U_{n}$ & Nominal control signal [V] \\
\hline$V_{A}$ & Chamber A volume $\left[\mathrm{m}^{3}\right]$ \\
\hline$v_{e s s}$ & Extending steady state velocity $[\mathrm{m} / \mathrm{s}]$ \\
\hline$v_{\max }$ & Maximum velocity $[\mathrm{m} / \mathrm{s}]$ \\
\hline$x$ & Piston displacement [m] \\
\hline$x_{\max }$ & Maximum desired step \\
\hline$y, y_{R e f}$ & Position and reference position [m] \\
\hline
\end{tabular}




\section{ACKNOWLEDGEMENTS}

This research was funded by China Three Gorgons Corporation of Brazil, Reivax S/A Automation and Control, and $\mathrm{CNPq}$ - Brazilian National Council for Scientific and Technological Development.

\section{REFERENCES}

[1] Bollmann A (1997) Fundaments of Pneutronic Industrial Automation - Design of Binary Electropneumatic Commands (in Portuguese). ABHP, São Paulo, Brazil

[2] Beater P (2007) Pneumatic Drives: System Design, Modelling and Control. Springer, Berlin, Germany

[3] Saravanakumar D, Mohan B, Muthuramalingam T (2017) A review on recent research trends in servo pneumatic positioning systems. Precision Engineering 49:481-492

[4] Rakova E, Hepke J, Weber J EXonomy analysis for the Inter-domain comparison of electromechanical and pneumatic drives. In: 10th International Fluid Power Conference, Dresden, Germany, 2016. pp $117-136$

[5] Conterato GP, Spada TAB, Vigolo V, Weiss LA, Leoncini LL, Araujo Pd, Negri VJD Modeling a pneumatic speed governor using eletronic pressure valves and directional valves. In: 25 th International Congress of Mechanical Engineering, Uberlândia, MG, Brazil, 2019.

[6] Hildebrandt A, Neumann R, Sawodny O (2009) Optimal system design of siso-servopneumatic positioning drives. IEEE transactions on control systems technology 1:35-44

[7] Canudas-de-Wit C, Olsson H, Astrom KJ, Lischinsky P (1995) A new model for control of systems with friction. IEEE Transactions on Automatic Control 40 3:419-425

[8] Vigolo V (2018) Theoretical-experimental study to aid the sizing of pneumatic actuation systems (in Portuguese). M.S. thesis, Federal University of Santa Catarina, Florianópolis, Brazil
[9] De Negri VJ, Ramos Filho JRB, Souza ADC (2008) A design method for hydraulic positioning systems. In: International Power Transmission Exposition, Las Vegas, 2008. Madison: Omnipress, pp 669-679

[10] Furst FL (2001) Systematization of the preliminary design of hydraulic circuits for position control (in Portuguese). M.S. Thesis, Federal University of Santa Catarina, Florianópolis, Brazil

[11] Oliveira LG (2009) Determination of the operating points for pneumatic cylinder-valve set (in Portuguese). M.S. thesis, Federal University of Santa Catarina, Florianópolis, Brazil

[12] Hené MD, Mendonza YEA, Oliveira LGD Determination of the operational point for the penumatic system sizing. In: 7th International Fluid Power Conference, Aachen, Germany, 2010. pp 343-354

[13] International Organization for Standardization (2013) ISO 6358-1 Pneumatic Fluid Power -Determination of flow rate characteristics of components using compressible fluids -- Part 1: General rules and test methods for steady-state flow. International Organization for Standardization,

[14] Mendonza YEA, De Negri VJ, Soares JMC (2014) Pneutronic Speed Governor for Small Hydropower Plants - A New Application for Pneumatics. Journal of the Brazilian Society of Mechanical Sciences and Engineering 8:2661-2633

[15] Mendoza YEA, de Oliveira LG, De Negri VJ Applicability of Servo-pneumatic Positioning Systems for High Loads. In: ASME Symposium on Fluid Power and Motion Control Bath, United Kingdom, 2008. pp 219-232

[16] International Electrotechnical Commission (2012) IEC 61362 - Guide to specification of hydraulic turbine governing systems. International Electrotechnical Commission, Switzerland

[17] Voith (1974) Electro-hydraulic regulator (EHR 74) - Descriptive manual (in Portuguese). 